\title{
The Selection and Development of High-efficiency Jerusalem Artichoke
}

\author{
Xue Zhizhong1, Yang Yahua ${ }^{1}$, Wu Zhe ${ }^{1}$, Wang Xiuping ${ }^{1}$, Jiang Jianmei ${ }^{2}$, Xu Tingting ${ }^{2}$ \\ ${ }^{1}$ Institute of Coastal Agriculture, Hebei Academy of Agricultural and Forestry Sciences,063200 \\ ${ }^{2}$ Tangshan Topo Biotechnology Co., Ltd.063020
}

Keywords: Jerusalem artichoke; Variety screening; Relaxing bowel

\begin{abstract}
This paper analyzes the sugar components of different Jerusalem artichoke (Helianthus tuberosus L.) tubers and their leaves. The results showed that the total sugar content of Jerusalem artichoke tuber accounted for more than $70 \%$ of dry weight. The content of inulin reached $77.5 \%$ on average, and the highest is "Binyu no.1" tuber. The content of inulin in the stem leaf was more than $11.73 \%$, reaching an average of $12.93 \%$. And the effect of inulin was then tested by functional test on constipation model mice. ICR male mice were randomly divided into blank control group, model control group, positive control group, low dose inulin group, medium dose inulin group and high dose inulin group. After 7 or 15 days of continuous inulin infusion, we observe the small intestine movement, initial stool time and amount of black stool. The results showed that inulin had a significant effect on constipation in mice. Finally, we analyse 27 varieties of Jerusalem artichoke by experiments, and select 6 varieties with high efficacy.
\end{abstract}

\section{Introduction}

Early studies have found that chronic constipation is related to water deficiency, decreased intestinal smooth muscle tone, slow intestinal peristalsis and disturbance of defecation muscle group. And in recent years, it has been found that intestinal flora imbalance plays an important role in the pathogenesis of chronic constipation. The colonic mucosa was disordered in the patients with refractory constipation, showing a decrease in diversity of colonic mucosa. However, as prebiotics, inulin can effectively improve the symptoms of constipation and reduce the incidence of constipation. These results suggest that inulin itself has the effect of relaxing bowel to relieve constipation. There are 36,000 species of plants known to contain inulin in nature. The inulin content of Jerusalem artichoke is between $64.81 \%$ and $77.54 \%$, and it is the plant with the highest inulin content.

Jerusalem artichoke is a perennial herb of the genus helianthus. It is wild and adaptable, which has low requirements on natural conditions such as climate and soil. The tubers of Jerusalem artichoke are rich in inulin, which can be used to produce ethanol. Jerusalem artichoke has strong adaptability, such as cold tolerance and drought resistance. The tuber contains a large amount of inulin and fructose, which is the raw material of sugar and syrup. Stems and leaves can be used as feed for rabbits, pigs, sheep, donkeys, horses, etc., which can be used directly for green feed in summer or for dry feed after being crushed in autumn. So, if we want to develop the Jerusalem artichoke industry, we must make full use of its tubers and leaves. So, we must master the difference between the tubers and leaves of different varieties, and then choose the right varieties in different directions.

In this study, through the analysis and comparison of six kinds of Jerusalem artichoke, this study revealed the varieties with high inulin nutrition composition. Then, the application of the high-efficiency variety was verified for animal function, which provided theoretical support for the comprehensive utilization and industrialization development of Jerusalem artichoke.

\section{Test 1: Effect of inulin on relaxing bowel}

In recent years, with the change of living rhythm, diet structure, behavior and living habits of modern people, as well as the influence of mental and psychological factors, the incidence of 
constipation has been on the rise. The incidence of constipation in population is $3 \% \sim 20 \%$, which seriously affects people's quality of life. The effect of inulin on constipation mice was tested as follows, which was used as a basis for developing health food with inulin as efficacy material.

\subsection{Test materials and methods}

\subsubsection{Test materials}

Inulin is provided by Zhengsheng nutrition technology (Beijing) co. LTD. ICR male mice were provided by the animal experiment center of China Medical University.

\subsubsection{The test methods}

A total of 120 ICR male mice were randomly divided into 6 groups, namely blank control group, model control group, positive control group, low dose inulin group, medium dose inulin group and high dose inulin group. There were 20 mice in each group and 10 mice in one group were fed for 7 and 15 days respectively. Each group was given basic feed. The blank control group and model control group were given normal saline of equal volume every day. Each dose group was given $0.2 \mathrm{ml} / 10 \mathrm{~g}$ of mice subjects per day, and the mice were given continuous gavage for 7 or 15 days. The recommended amount of inulin is $10 \mathrm{~g} / \mathrm{d}$, which is prepared into an aqueous solution before perfusion.

\subsubsection{Modeling and measurement indexes}

Given the drugs for 7 or 15 days, the mice in each group fasted for 16 hours. The blank control group was given lavage distilled water, the model control group, the positive control group and each dose group were given lavage $(10 \mathrm{mg} / \mathrm{kg})$. After half an hour, the positive control group was given the positive drug. The ink was given to each dose group. In the blank control group and the model control group, lavage ink was administered with a dosage of $0.2 \mathrm{ml} / 10 \mathrm{~g}$. The mice were raised in a single cage and fed and drank normally. The recommended amount of inulin is $10 \mathrm{~g} / \mathrm{d}$. The medium dose inulin group is $20 \mathrm{~g} / \mathrm{d}$ and the high dose inulin group is $30 \mathrm{~g} / \mathrm{d}$. The time of first black stool drainage, the number of black stool pellets and weight of each mouse were recorded within $6 \mathrm{~h}$ after lavage instillation.

\subsection{Results and analysis}

\subsubsection{The test results}

Table 1 shows the effect of the 7-day test on defecation in mice. Table 4 shows the effect of 15 -day test on defecation in mice.

Table 1 Effects of inulin on first stool time and quantity of black stool (7 days)

\begin{tabular}{lllll}
\hline \multicolumn{1}{c}{ Group } & $\begin{array}{c}\text { Number of } \\
\text { sample }\end{array}$ & $\begin{array}{c}\text { First defecation } \\
\text { time } / \mathrm{min}\end{array}$ & $\begin{array}{c}\text { Number of } \\
\text { black stool(6h) }\end{array}$ & $\begin{array}{c}\text { Weight of black } \\
\text { stool(6h) }\end{array}$ \\
\hline blank control group & 10 & $74.28 \pm 26.31$ & $16.50 \pm 1.60^{* *}$ & $6 \pm 0.1362^{* *}$ \\
model control group & 10 & $120.13 \pm 27.44^{* *}$ & $11.75 \pm 3.37$ & $0.2351 \pm 0.0784$ \\
positive control group & 10 & $45.38 \pm 16.71^{* * *}$ & $15.75 \pm 2.87^{*}$ & $0.3707 \pm 0.0873^{*}$ \\
low dose inulin group & 10 & $34.48 \pm 15.37^{* * *}$ & $20.38 \pm 3.623^{* *}$ & $0.3319 \pm 0.0569^{* *}$ \\
medium dose inulin group & 10 & $19.33 \pm 5.77^{* * *}$ & $25.58 \pm 5.85^{* * *}$ & $0.4619 \pm 0.1321^{* *}$ \\
high dose inulin group & 10 & $15.05 \pm 22.01^{* * *}$ & $29.78 \pm 9.06^{* * *}$ & $0.5338 \pm 0.0828^{* *}$ \\
\hline
\end{tabular}

Note: * the significant difference was $\mathrm{P}<0.05$; ** means the difference is extremely significant $\mathrm{P}<0.01 ; * * *$ means the difference height is significant $\mathrm{P}<0.001$. 
Table 2 Effects of inulin on first stool time and quantity of black stool (15 days)

\begin{tabular}{lllll}
\hline \multicolumn{1}{c}{ Group } & $\begin{array}{c}\text { Number of } \\
\text { sample }\end{array}$ & $\begin{array}{c}\text { First defecation } \\
\text { time /min }\end{array}$ & $\begin{array}{c}\text { Number of } \\
\text { black stool(6h) }\end{array}$ & $\begin{array}{c}\text { Weight of black } \\
\text { stool(6h) }\end{array}$ \\
\hline blank control group & 10 & $92.53 \pm 7.50^{*}$ & $18.13 \pm 2.90^{* *}$ & $0.4436 \pm 0.1242^{* *}$ \\
model control group & 10 & $130.50 \pm 20.21$ & $8.450 \pm 1.67$ & $0.2315 \pm 0.0874$ \\
positive control group & 10 & $84.13 \pm 11.06^{* *}$ & $13.50 \pm 1.07^{* *}$ & $0.3624 \pm 0.0945^{* *}$ \\
low dose inulin group & 10 & $57.33 \pm 13.59^{* *}$ & $12.30 \pm 2.07^{* *}$ & $0.3782 \pm 0.1356^{* *}$ \\
medium dose inulin group & 10 & $40.50 \pm 13.15^{* *}$ & $16.53 \pm 4.66^{* *}$ & $0.4571 \pm 0.1275^{* *}$ \\
high dose inulin group & 10 & $30.63 \pm 15.94^{* *}$ & $18.28 \pm 3.02^{* *}$ & $0.4718 \pm 0.0936^{* *}$ \\
\hline
\end{tabular}

Note: * the significant difference was $\mathrm{P}<0.05$; $* *$ means the difference is extremely significant $\mathrm{P}<0.01$.

\subsubsection{The test analysis}

When the first defecation time of mice was taken as the indicator, the difference between the model group and the blank control group was extremely significant $(\mathrm{P}<0.01)$, indicating that the modeling was successful. The results of each index indicated that the positive control group and each dose group had a shortening effect on the first stool time, or an increase effect which lavage high dose of inulin on the amount of defecation. The first fecal time of mice was taken as the indicator. In the $7 d$ experiment, the first defecation time of all dose groups was significantly shorter than that of the positive drug, which was statistically significant $(\mathrm{P}<0.05)$. In the $15 \mathrm{~d}$ experiment, all the dose groups were shorter than the positive group and which was statistically significance $(\mathrm{P}<0.05)$.

Number of black stool (6h) was taken as the index. In the 7 day experiment, low dose inulin group, medium dose inulin group and high dose inulin group was significantly stronger than that in the positive group $(\mathrm{P}<0.05)$. And with the increase of dose, the effect was more significant. In the 15 day experiment, low dose inulin group, medium dose inulin group and high dose inulin group was significantly stronger than that in the positive group $(\mathrm{P}<0.01)$. And with the increase of dose, the effect was more significant. So, inulin dose has a significant effect on nourishing enteral laxative.

\section{Test 2: Selection of high inulin varieties}

\subsection{Test materials and methods}

\subsubsection{Test materials}

27 kinds of Jerusalem artichoke tuber harvest, wash with ultra-pure water and dry naturally. The tubers and stems leaves were crushed and screened with $0.25 \mathrm{~mm}$ sieve for sealing preservation. Finally, the nutrient composition of the powder was determined. The test reagents include anhydrous ethanol, sulfuric acid, formaldehyde, sodium hydroxide potassium sodium tartrate, copper sulfate, anhydrous glucose, potassium sulfate, methylene blue, methyl red, etc. The Analytical Reagent are all made in China.

\subsubsection{Test method}

Reducing sugars were determined by the capacity method of GB/T 5009.7-2008. The total sugar is transformed into reducing sugar after hydrolysis by hot sulfuric acid, and then determined by film reagent capacity method. Inulin is a non-reducing polysaccharide. The content of inulin is determined by total sugar minus reducing sugar.

\subsection{Results and analysis}

\subsubsection{The test results}

The nutritional components of different Jerusalem artichoke tuber were shown in table 3, and the stems leaves were shown in table4. 


\subsubsection{The test analysis}

Inulin has the function of relaxing bowel, and is an important raw crop extracted from relaxing bowel medicine. Therefore, the higher the content, the better. The varieties suitable for medicine are listed in table 4. Crops with high total sugar content and protein content of $6 \% \sim 10 \%$ are important industrial raw materials, especially as raw materials for alcohol. The varieties suitable for industrial raw materials selection are shown in table 5. Protein content and ash content are important indexes to evaluate the nutritional value of feed crops. The indexes of good feed are protein content of $9 \% \sim 18 \%$ and ash content of $5 \% \sim 6 \%$. The varieties suitable for feed selection are shown in table 6 .

Table 3 Results of tuber nutrition analysis (g/100g)

\begin{tabular}{|c|c|c|c|c|c|c|c|c|}
\hline NO. & Varieties & Seed location & Ash & Protein & Fat & $\begin{array}{l}\text { Total } \\
\text { sugar }\end{array}$ & $\begin{array}{l}\text { Reducin } \\
\text { g sugar }\end{array}$ & Inulin \\
\hline 1 & $\begin{array}{l}\text { TY3B3: } \\
\text { H29 }\end{array}$ & Tanghai city & 6.1 & 11.1 & 0.9 & 8.6 & 7.2 & 1.4 \\
\hline 2 & LNDD & Liaoning city & 5.3 & 9.38 & 1.3 & 10.3 & 7.3 & 3 \\
\hline 3 & ZKY1 & CAS & 5.5 & 10.6 & 1.3 & 8.1 & 6.6 & 1.5 \\
\hline 4 & NY2 & $\begin{array}{l}\text { Nanjing agricultural } \\
\text { university }\end{array}$ & 6.7 & 10.2 & 2.1 & 9.2 & 7.4 & 1.8 \\
\hline 5 & ZKY1 & CAS & 6.2 & 10.6 & 0.8 & 8.9 & 6.9 & 2 \\
\hline 6 & JY4 & $\begin{array}{l}\text { Jilin academy of } \\
\text { agricultural sciences' }\end{array}$ & 6.4 & 11 & 1 & 8.83 & 8.1 & 0.73 \\
\hline 7 & QY2 & Qinhaungdao city & 6.4 & 10.6 & 1 & 9.6 & 7.8 & 1.8 \\
\hline 8 & NY2 & $\begin{array}{l}\text { Nanjing agricultural } \\
\text { university }\end{array}$ & 6.2 & 10.6 & 1 & 8.9 & 7.9 & 1 \\
\hline 9 & DQ24 & $\begin{array}{l}\text { Heilongjiang academy of } \\
\text { agricultural sciences' }\end{array}$ & 6.3 & 10.2 & 0.6 & 9.1 & 6.9 & 2.2 \\
\hline 10 & BJ & Beijing city & 6.9 & 11.4 & 0.9 & 8.8 & 6.3 & 2.5 \\
\hline 11 & DQ4 & $\begin{array}{l}\text { Heilongjiang academy of } \\
\text { agricultural sciences' }\end{array}$ & 5.2 & 7.5 & 1.2 & 9.7 & 8.2 & 1.5 \\
\hline 12 & LY8 & $\begin{array}{l}\text { Langfang academy of } \\
\text { agricultural sciences' }\end{array}$ & 7.1 & 11.6 & $\begin{array}{c}10 . \\
3\end{array}$ & 9.3 & 7.3 & 2 \\
\hline 13 & Binyu 1 & $\begin{array}{l}\text { Hebei academy of } \\
\text { agricultural sciences' }\end{array}$ & 5.9 & 9.8 & 0.8 & 9.5 & 6.9 & 2.6 \\
\hline 14 & HBHS & Hengshui city & 5.7 & 11.4 & 0.9 & 9.6 & 7.4 & 2.2 \\
\hline 15 & DQ4 & Daqing city & 6.2 & 9.86 & 0.6 & 10.4 & 8.1 & 2.3 \\
\hline 16 & HLY5 & $\begin{array}{l}\text { Heilongjiang academy of } \\
\text { agricultural sciences' }\end{array}$ & 6.3 & 11.5 & 1 & 13.4 & 10 & 3.4 \\
\hline 17 & HBBD & Baoding city & 6.2 & 10.6 & 0.6 & 12 & 7.8 & 4.2 \\
\hline 18 & JSSQ & Jiangsu province & 6.5 & 8.64 & 0.7 & 15 & 12.1 & 2.9 \\
\hline 19 & LNZY & Liaoning province & 6.6 & 14.5 & 0.8 & 10 & 7.2 & 2.8 \\
\hline 20 & HHY & Huanghua city & 6.1 & 10.3 & 0.6 & 8.8 & 7 & 1.8 \\
\hline 21 & JY1 & $\begin{array}{l}\text { Jilin academy of } \\
\text { agricultural sciences' }\end{array}$ & 6.5 & 10.9 & 1.2 & 8.3 & 6.7 & 1.6 \\
\hline 22 & QHY3 & $\begin{array}{l}\text { Qinghai academy of } \\
\text { agricultural sciences' }\end{array}$ & 5.6 & 9.92 & 0.6 & 9.6 & 7.2 & 2.4 \\
\hline 23 & DQ11 & $\begin{array}{l}\text { Heilongjiang academy of } \\
\text { agricultural sciences }\end{array}$ & 5.4 & 11.8 & 1.1 & 9.7 & 8.1 & 1.6 \\
\hline 24 & JY3 & $\begin{array}{l}\text { Jilin academy of } \\
\text { agricultural sciences }\end{array}$ & 5.8 & 10 & 1.5 & 9 & 7.5 & 1.5 \\
\hline 25 & MY1 & $\begin{array}{l}\text { Inner Mongolia academy of } \\
\text { agricultural sciences }\end{array}$ & 7 & 11.6 & 0.8 & 8.4 & 6.8 & 1.6 \\
\hline 26 & QY1 & Hebei city & 5.8 & 10.2 & 0.6 & 6.19 & 5.3 & 0.89 \\
\hline 27 & LNCY & Liaoning city & 6.3 & 13.6 & 0.9 & 9.9 & 8.1 & 1.8 \\
\hline
\end{tabular}


Table 4 Selection of breed feed

\begin{tabular}{|r|l|r|}
\hline NO & Varieties & Inulin \\
\hline 1 & LNDD & 3 \\
\hline 2 & BJ & 2.5 \\
\hline 3 & Binyu 1 & 2.6 \\
\hline 4 & HLY5 & 3.4 \\
\hline 5 & HBBD & 4.2 \\
\hline 6 & JSSQ & 2.9 \\
\hline 7 & LNZY & 2.8 \\
\hline
\end{tabular}

Table 5 Selection of industrial materials

\begin{tabular}{|r|l|l|r|}
\hline NO & Varieties & Protein & \multicolumn{1}{|c|}{ Total sugar } \\
\hline 1 & LNDD & 9.38 & 10.3 \\
\hline 2 & DQ4 & 7.5 & 9.7 \\
\hline 3 & Binyu 1 & 9.8 & 9.5 \\
\hline 4 & DQ4 & 9.86 & 10.4 \\
\hline 5 & JSSQ & 8.64 & 15 \\
\hline 6 & QHY3 & 9.92 & 9.6 \\
\hline 7 & JY3 & 10 & 9 \\
\hline \multicolumn{2}{|r|}{}
\end{tabular}

Table 6 Selection of breed feed

\begin{tabular}{|r|l|r|r|}
\hline NO & Varieties & Ash & Protein \\
\hline 1 & ZKY1 & 5.5 & 10.6 \\
\hline 2 & Binyu 1 & 5.9 & 9.8 \\
\hline 3 & HBHS & 5.7 & 11.4 \\
\hline 4 & QHY3 & 5.6 & 9.92 \\
\hline 5 & DQ11 & 5.4 & 11.8 \\
\hline 6 & JY3 & 5.8 & 10 \\
\hline 7 & QY1 & 5.8 & 10.2 \\
\hline
\end{tabular}

Statistical results of the three functions are shown in figure 1.

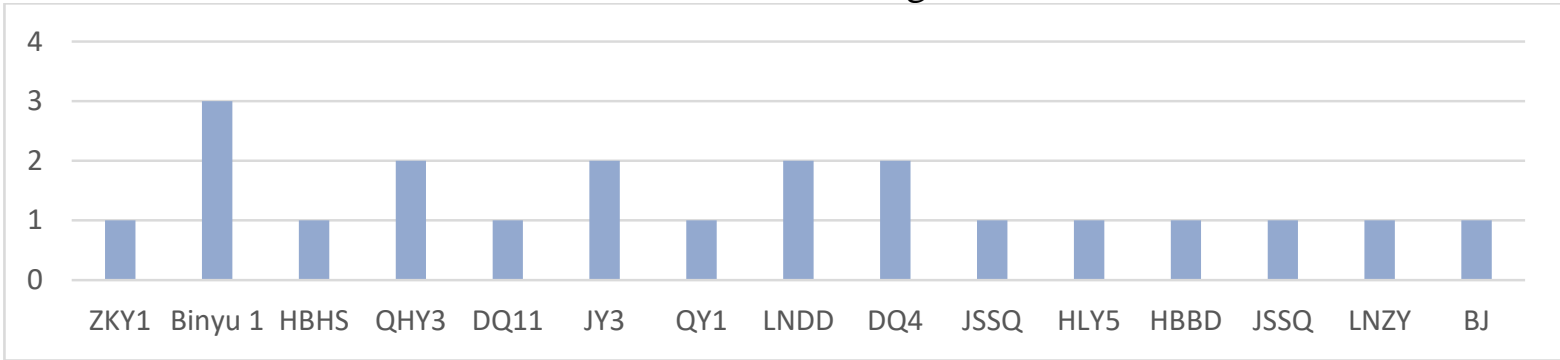

Figure 1 Statistical results of the three functions

\section{Conclusions}

According to test 1, inulin has a significant effect on constipation test mice, and it can be proved that inulin has a significant effect on human relaxing bowel. Many studies show that Jerusalem artichoke is the most abundant plant among plants known to contain inulin.

Therefore, 27 varieties of Jerusalem artichoke were analyzed for their nutritional composition. Hope to be able to choose the variety of Jerusalem artichoke which is relaxing bowel, and have the characteristic of high effect. Among them, Binyu 1, QHY3, JY3 and QY1 have high efficacy.

\section{References}

[1] Frese L, Dambroth M, Branlln A. Breeding potential of root chieory[J].Plant Breeding, 1991, 106(2):107-113. 
[2] Bubnik Z, KOrcakova I, Kadlee P, et al. Isolation of inulin from chicory root [J]. Czech Journal of Food Sciences, 1997, 15(1):49-67.

[3] Cudmore S, Doolan A, Lacey S, et al. A randomised, double-blind, placebo-controlled clinical study: the effects of a synbiotic, Lepicol, in adults with chronic, functional constipation [J]. Int $\mathrm{J}$ Food Sci Nutr,2016,24: 1-12.

[4] Micka A, Siepelmeyer A, Holz A, et al.Effect of consumption of chicory inulin on bowel function in healthy subjects with constipation: a randomized, double-blind, placebo-controlled trial[J]. Int J Food Sci Nutr,2016,5: 1-8

[5] Xue zhizhong, Yang yahua, li keye, zhang guoxin, liu shujun. Advances in research on salinity tolerance of Jerusalem artichoke[J]. Hebei academy of agriculture and forestry. 2014. 